\title{
Efeitos da descentralização nas relações intergovernamentais: o Brasil em perspectiva comparada
}

TUA FAUEI*

\section{Introdução}

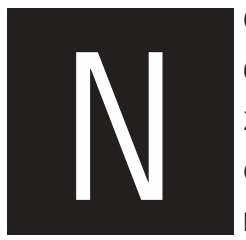

o começo da década de 80, o Brasil começou a se distanciar da política desenvolvimentista e do governo centralizado. As eleições diretas para governador foram realizadas em 1982, antes, porém, da eleição direta para presidente, restabelecida em 1989. Ademais, nas duas décadas seguintes, ocorreu significativa descentralização de recursos financeiros e da prestação de serviços sociais para estad os e municípios. Considerando que, tanto em termos territoriais quanto populacionais, o Brasil é o quinto maior país do mundo, não é de surpreender que, com o término do modelo econômico desenvolvimentista e da ditadura militar (1964-1985), o país assumisse a descentralização do governo como parte do processo de redemocratização. 0 s resultados da descentralização, contudo, são extremamente intrigantes.

Conquanto historicamente o Brasil tenha tido uma estrutura de governo descentralizada, o processo de descentralização pós-desenvolvimentista aumentou ainda mais os recursos financeiros, a responsabilidade pela for-

\footnotetext{
* Assistant Professor of Political Science, U niversity of Pennsylvania (Philadelphia, USA).

1 Agradeço a Emily Edmonds-Poli, M aria Escobar-Lemon e Celina Souza pelos comentários a uma versão anterior deste artigo. Argelina Figueiredo e Celina Souza forneceram orientações acadêmicas inestimáveis so bre descentralização e política brasileiras, além de generosa hospitalidade quando estive no Brasil. A pesquisa de campo no Brasil foi concluída durante o verão de 2005 e foi financiada com recursos do Christopher Browne Center for International Relationse da School of Arts and Sciences da U niversidade da Pennsylvania.
} 
mulação de políticas públicas e a autoridade política dos governos subnacionais, o que mostra que não existe limite estrutural de quanto poder pode ser transferido para as unidades subnacionais. ${ }^{2} \mathrm{~N}$ o início da década de 80 , as condições de equilíbrio intergovernamental do poder no Brasil eram semelhantes às da Argentina. Duas décadas mais tarde, porém, as mudanças nas relações intergovernamentais no Brasil aproximaram o Brasil da Colômbia pelo elevado grau de mudança e de devolução de poder para as esferas subnacionais, ao tempo em que o distanciou da Argentina. Por que, tendo iniciado o processo de descentralização pós-desenvolvimentista com uma estrutura intergovernamental semelhante à da Argentina, as relações intergovernamentais brasileiras sofreram alterações profundas, tais como as experimentadas por um país unitário como a Colômbia, enquanto as relações intergovernamentais da Argentina permaneceram praticamente as mesmas?

Ao comparar o processo de descentralização brasileiro ao processo experimentado por outros países da América Latina, argumento, neste artigo, que as mudanças que as reformas descentralizadoras trazem para a distribuição de poder entre os governos nacional e os subnacionais dependem da seqüência em que diferentes tipos de reformas políticas descentralizadoras (administrativa, fiscal e política) acontecem. 0 artigo mostra que o tipo de distribuição territorial de poder estabelecido pelas constituições - federal ou unitário - , o grau de descentralização do sistema que rege os partidos políticos - se os legisladores nacionais são mais leais aos líderes nacionais ou aos subnacionais -, e as condições iniciais das estruturas de relações intergovernamentais não afetam, em grande medida, as mudanças que políticas descentralizadoras promovem nas relações

2 Conceituo descentralização pós-desenvolvimentista como o processo de reformas nas políticas públicas que transferiu recursos, responsabilidades e/ou autoridade política do governo central para os governos subnacionais após o fim do Estado desenvolvimentista. Entre outras características, o modelo desenvolvimentista de crescimento econômico se caracterizava por altos níveis de envolvimento direto do Estado nacional na economia. Na maioria dos países da América Latina, esse modelo de crescimento econômico sofreu um colapso entre o final dosanos 70 ou no início dosanos 80 , dando lugar a subseqüentes reformas estatais profundas. Para uma definição abrangente de Estado desenvolvimentista, ver Schneider (1999). 
intergovernamentais. Em outras palavras, argumento em favor de uma explicação dependente (path dependent) da via processual e contra explicações de legados estruturais e institucionais de longo prazo para explicar as conseqüências da descentralização sobre o equilíbrio intergovernamental do poder. Enfatizarei, portanto, a importância de processos de médio prazo e de contextos específicos, ao invés da perpetuação dos legados institucionais de longo prazo para o estudo da forma como as políticas de descentralização remodelaram o equilíbrio intergovernamental do poder no Brasil.

0 artigo está organizado da seguinte forma: na próxima seção, comparo a evolução das relações intergovernamentais no Brasil, na Argentina, na Colômbia e no M éxico, do final da década de 70 ao final da década de 90 . Após apresentar algumas explicações alternativas sobre as razões dessa evolução, proponho uma teoria seqüencial da descentralização, que contém três características principais. Em primeiro lugar, a teoria seqüencial da descentralização define descentralização como um processo tridimensional de política pública. Em segundo, a teoria leva em consideração os interesses territoriais dos políticos nacionais e subnacionais em relação a essas três dimensões. Por fim, a teoria considera o impacto de diferentes seqüências de reformas descentralizadoras no equilíbrio intergovernamental do poder. Aplico, então, a teoria à análise das reformas descentralizadoras pós-desenvolvimentistas que aconteceram no Brasil a partir da administração de João Figueiredo e estudo seu impacto nas relaçõesintergovernamentais. A última seção conclui destacando a importância das análises guiadas pelo processo e que dedicam atenção especial a questões de contexto e de médio prazo.

Relações Intergovernamentais no Brasil: comparações com a Argentina, a Colômbia e o México

D os primórdios da República brasileira até a ascensão de Getúlio Vargas ao poder nacional, os governadores dos estados foram os principais porta- 
vozes da República Velha. Esse período, que se estendeu de 1899 a 1930, caracterizou-se pela chamada "Política dos Governadores", devido ao surgimento de um sistema federal altamente descentralizado, em que os governadores dos estados mais poderosos - São Paulo, M inas Gerais e Rio de Janeiro - dominavam a política do País (Samuels, 2004: 70). Embora o períod o político seguinte (1930-1945) tenha sido caracterizado pela tentativa de Vargas de centralizar o poder no Executivo federal, os estados permaneceram importantes. Por exemplo, entre 1938 e 1945, a arrecadação de impostos estaduais representava $56 \%$ dos impostos nacionais, em comparação com $17 \%$ no M éxico (também um Estado federal) durante o mesmo período (Love apud Samuels, 2004: 71). No período democrático de 1946 a 1964, os governadores recuperaram o poder político institucional que haviam perdido com Vargase, embora o regime militar subseqüente (19641985) tenha reduzido significativamente recursos financeiros e poder político, as elites políticas estaduais permaneceram importantes atores no cenário político (Abrucio, 1998; Hagopian, 1996; Samuels, 2004: 75-78).

Dessa forma, no começo dos anos 80, o Brasil, junto com a Argentina, era um dos países mais descentralizados da América Latina em termos de recursos, responsabilidades e autoridade política delegados aos governos subnacionais. A Tabela 1 compara a evolução de cinco variáveis que, juntas, respondem pelo equilíbrio intergovernamental do poder entre autoridades nacional e subnacionais no Brasil, na Argentina, na Colômbia e no M éxico. A tabela mostra ainda o equilíbrio intergovernamental do poder antese depois do processo de descentralização pós-desenvolvimentista e o grau relativo das alterações ocorridas em cada um desses paises.

Diversos fatores fazem da Argentina, da Colômbia e do M éxico países adequados para a comparação com o Brasil. Primeiro, por causa do tamanho territorial, dado que estes são os três maiores países na América Latina após o Brasil, pode-se presumir que as relações entre os centros e as peri- 
ferias são conflitantes e que questões acerca da descentralização são politicamente relevantes. Segundo, os três países passaram por processos de descentralização semelhantes ao do Brasil em termos administrativos, fiscais e políticos, embora com resultados diferentes no que se refere à distribuição intergovernamental do poder. Terceiro, a Argentina, a Colômbia e o M éxico possuem estruturas de governo comparáveis à do Brasil: todos têm três níveis de governo e sistema legislativo nacional bicameral. Por fim, as diferenças entre o Brasil e ao menos um dos outros países servem como variável de controle para o argumento principal aqui desenvolvido. Por um lado, a Argentina e o México, como o Brasil, são países federais, mas a Colômbia é um Estado unitário. Por outro lado, a Argentina e a Colômbia, como o Brasil, possuem sistemas partidários descentralizados, enquanto que no M éxico o sistema é centralizado.

$\mathrm{Na}$ Tabela 1, as duas primeiras colunas medem o nível absoluto de descentralização de cada país através do conteúdo dos seus sistemas fiscal, administrativo e político, e a terceira coluna mede o grau relativo de alterações no equilíbrio intergovernamental do poder. Em relação às dimensões fiscais, a parcela subnacional nas receitas (PSR), que registra o total das receitas arrecadadas pelos governos subnacionais, tanto estaduais quanto municipais, diminuiu na Argentina, mas aumentou nos outros três países, enquanto a parcela subnacional nos gastos (PSG), que registra o total de recursos alocado pelos governos subnacionais, tanto estaduais quanto municipais, aumentou nos quatro países. No início dos anos 80, o Brasil e a Argentina tinham os mais elevados níveis absolutos de descentralização fiscal, tanto em termos de receita quanto de gastos, seguidos pela Colômbia e depois pelo M éxico. Da metade para o final dos anos 90 , surgiu um padrão diferente. 0 Brasil continuou send o o país mais descentralizado em termos fiscais, mas a Colômbia tornou-se o segundo país nestas condições, e na PSR, o M éxico ultrapassou a Argentina, que registrou a menor arreca- 
Sociologias, Porto Alegre, ano 8, no 16, jul/dez 2006, p. 46-85

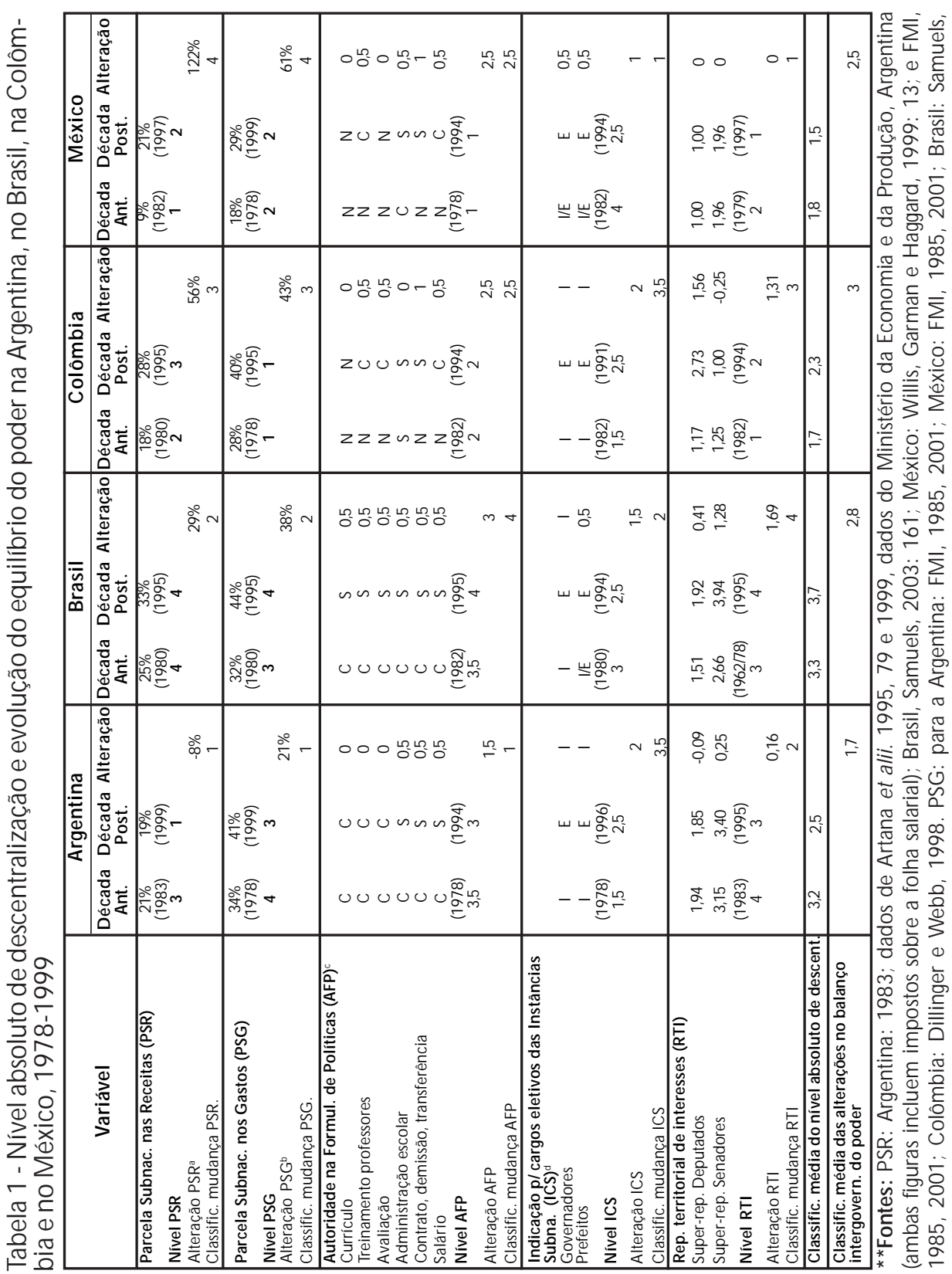


dação de receitas subnacionais e o maior desequilíbrio fiscal dos quatro países. Em relação às condições iniciais, como mostra a terceira coluna, o M éxico passou pela maior alteração na sua estrutura fiscal, seguido pela Colômbia e pelo Brasil. A Argentina foi o país que sofreu menos alterações no campo fiscal global, experimentando, inclusive, redução na PSR.

Em relação à administração dos serviços sociais, a dimensão autoridade para formulação de políticas (AFP) é testada para o setor da educação. ${ }^{3}$ O s seis indicadores levados em consideração nessa dimensão são autoridade sobre currículos; responsabilidade pelo treinamento dos professores; responsabilidade pela avaliação do sistema educacional; administração das escolas; autoridade para contratar, demitir e transferir professores e autoridade sobre a fixação dos salários.

\footnotetext{
**Continuação Tabela $1 . .$.

2003; Colômbia: FMI, 1985 e Dillinger e W ebb, 1998: 21. AFP: dados coletados de fontes secundáriase leis de educação. ICS: dados coletados de fontes secundárias e constituições nacionais. RTI: para a Argentina: Constituição Nacional e INDEC 1997; México: Lujambo, 2000: 35, 73-76, e INEGI 1995; Brasil: dados fornecidos por David Samuels; Colômbia: Registraduría Nacional del Estado Civil (diversos anos).

O bservação: 0 s números em negrito classificam os países por nível absoluto de descentralização: de 1, mais centralizado, a 4, mais descentralizado. As médias do nível absoluto de descentralização para cada país são apresentadas na penúltima linha. O snúmeros em negrito e itálico classificam os países por grau de alteração em cada dimensão do equilíbrio intergovernamental do poder, de 1, correspondendo ao país que sofreu menos alterações, a 4, que corresponde ao país que sofreu mais alterações. O grau médio de alteração do equilíbrio intergovernamental do poder em cada país é apresentado na última linha.

${ }^{a}$ Alteração PSR = (PSR post. - PSR ant.)/PSR ant.

${ }^{b}$ Alteração PSG = (PSG post. - PSG ant.)/PSG ant.

'AFP: N : Nacional, C: Concorente, S: Subnacional. 0 valor de alteração de AFP é 0, se o nível de autoridade não se alterou; 1 , se a autoridade passou de $\mathrm{N}$ para S; e 0,5, se passou de $\mathrm{N}$ para $\mathrm{C}$ ou de $\mathrm{C}$ para S.

${ }^{d}$ ICS: E: Eleito, I: Indicado, I/E: apenas formalmente eleito ou com indicação para alguns cargos. Alteração ICS: 0 valor é 0 , se o tipo de indicação não se alterou; 1 , se passou de I para E; e 0,5, se passou de I/E para E, ou de I para I/E.

e O s valores de alteração RTI resultam da diminuição do valor RTI ant. do valor RTI post.
}

3 A escolha da educação, entre outros setores, deve-se a diversas razões. Em primeiro lugar, tanto em termos fiscais quanto de recursos humanos, a educação representa a maior parcela do setor público nesses países. A transferência de responsabilidade sobre a educação traz, portanto, conseqüências fiscais e administrativas significativas para estados e municípios. Em segundo, o setor da educação freqüentemente tem sindicatos fortes e grandes. Isso faz com a descentralização da educação seja politicamente crucial para os Executivos subnacionais e nacional, que precisam negociar com esses sindicatos. Por fim, na maioria dos países, a educação foi o primeiro setor a ser descentralizado, influenciando o ritmo e as características da descentralização em outras áreas. No Brasil, contudo, após o término do Estado desenvolvimentista, a descentralização dos serviços de saúde precedeu a descentralização dos programas educacionais (de estados para os municípios) e dos recursos (da União para os municípios). Por isso, a seção sobre descentralização administrativa no Brasil apresentada adiante focaliza principalmente a descentralização dos serviços de saúde, mas, para propósitos comparativos, o setor educacional é analisado nesta seção. 
No começo do período analisado, os países podiam ser unidos em pares, em termos de distribuição das responsabilidades entre os níveis do governo: o Brasil e a Argentina eram os mais descentralizados, o M éxico e a Colômbia, os mais centralizados. Ao final do período, a ordenação dos países continuava semelhante, mas o Brasil experimentou nível maior de devolução de autoridade para instâncias subnacionais do que a Argentina. Ao passo que, em 1982, as autoridades municipais, estaduais e o governo federal brasileiros dividiam as responsabilidades em relação aos indicadores educacionais, sem uma definição de suas responsabilidades exclusivas (Draibe, 2004: 387, 392; Tavares de Almeida, 1995: 20, 27-28), na metade dos anos 90 , todas estas tarefas passaram para os governadores, os prefeitos ou os diretores de escolas (Burki, Perry e Dillinger, 1999: 71). O México e a Colômbia seguiram o Brasil no grau de mudanças na AFP. No M éxico, todas as questões relacionadas à administração da educação pública estavam, em 1978, nas mãos do governo federal, com a única exceção para a administração dos prédios das escolas, que era uma responsabilidade compartilhada. Em 1992, após a assinatura do acordo de descentralização, a autoridade sobre os currículos e sobre a avaliação do sistema permaneceu na esfera federal, mas todas as outras questões passaram a ser decididas nas esferas subnacionais, ou conjuntamente pelos níveis nacional e subnacionais de governo. A situação no setor da educação na Colômbia no início da década de 80 era semelhante à do $M$ éxico: todas as responsabilidades eram do governo federal, com exceção da manutenção das escolas, de responsabilidade subnacional. No entanto, após a descentralização da educação em 1992 e 1993, todas as questões educacionais tornaram-se responsabilidade das autoridades estaduais, com a única exceção dos parâmetros curriculares, que permaneceram com o governo central. $\mathrm{Na}$ Argentina, a situação era diferente. Na metade da década de 70, as províncias argentinas administravam metade das escolas públicas de ensino primário e secundário, o que significava que todas as responsabilidades em 
relação ao sistema educacional público eram compartilhadas entre o governo federal e os governos das províncias. A descentralização das escolas primárias e secundárias, ocorrida em 1978 e 1992 respectivamente, não alterou a distribuição da autoridade formal entre os níveis governamentais. A mudança deu-se somente após a aprovação de uma nova lei federal sobre educação, em 1993, quando algumas questões passaram ao domínio exclusivo das províncias (Corrales, 2004). Como se pode ver na Tabela 1, em termos da AFP, o Brasil registrou o maior grau de alteração, seguido pelo México, pela Colômbia e pela Argentina.

Duas dimensões são responsáveis pela distribuição de poder na arena política. A primeira é a forma de indicação para os cargos eletivos das instâncias subnacionais (ICS). N essa dimensão, a Colômbia e a Argentina foram as que registram as maiores alterações. Na Colômbia, desde 1886, prefeitos e governadores eram indicados, até a introdução da eleição por voto popular, em 1988 e 1991, respectivamente. Na Argentina, embora os cargos eletivos subnacionais tenham sido historicamente preenchidos através do voto popular, durante a última ditadura militar (1976-1983), quando se iniciou o processo de descentralização pós-desenvolvimentista, eles passaram a ser nomeados. 0 Brasil seguiu a rota da Colômbia e da Argentina em relação ao grau de mudança na ICS. Em 1966, o regime militar suspendeu a eleição direta para governadores e prefeitos nas capitais de estado e em outros municípios consideradosáreas de "segurança nacional" (Skidmore, 1988: 107), o que incluía municípios com grande presença militar, alguns municípios nas fronteiras e outros com instalações hid relétricas e exploração mineral. Os governadoreseram eleitos através das Assembléias Legislativas estaduais, após a aprovação de seus nomes pelos militares. Através do controle do nome dos candidatos, os militares interferiam diretamente na nomeação dos governadores, indicando qual candidato deveria ser eleito pelas Assembléias Legislativas estaduais (Santos, 1971: 123). O s prefeitos das capitais e dos municípios de importância estratégica, que, em 1985, 
totalizavam 201, eram indiretamente eleitos pelas Assembléias Legislativas, ao passo que os prefeitos dos 3.790 municípios restantes e das Câmaras de Vereadores eram escolhidos através de eleições diretas. ${ }^{4}$ As eleições diretas para governador foram restabelecidas em 1982, e as eleições por voto popular para prefeitos das capitais e municípios de "segurança nacional" foram restabelecidas em 1985. N o M éxico, por fim, havia eleições para os cargos eletivos das instâncias subnacionais, com exceção do prefeito da Cidade do México, mas elas não eram competitivas. Somente na metade da década de 90 as eleições para prefeitos e governadores tornaram-se, em geral, competitivas no México.

A segunda dimensão política é a representação territorial de interesses (RTI). Nessa dimensão, os coeficientes de super-representação mostram o grau de desvio do princípio "um cidadão, um voto". U m valor de coeficiente 1 indica proporcionalidade entre o número de representantese a população do estado. Se o coeficiente de super-representação for maior que 1 , significa que, em algumas unidades subnacionais, o "custo" de eleger um deputado ou um senador é mais baixo do que em outras. Nas palavras de Stepan (2000), quanto maior o coeficiente, mais restritivos do poder da pólis (demos-constraining) os Senados e Câmaras. Q uanto maiores forem os coeficientes de super-representação, mais fácil será para alguns deputados e senadores representarem os interesses territoriais de suas unidades subnacionaise de seus eleitores, ao invés dos interesses da maioria política. O Brasil e a Colômbia são os países que experimentaram os maiores graus de alteração na super-representação em cada uma ou em ambas as instâncias legislativas nacionais. No Brasil, a criação de dois novos estados (M ato Grosso do Sul e Tocantins) e as mudanças introduzidas pela Constituição de 1988 fizeram com que, entre 1962 e 1995, o grau de super-

4 Em 1976, 3.790 municípios elegeram seus prefeitos. Em 1982, o número aumentou para 3.941 (Lamounier, 1990: 184, 187). Semelhante ao procedimento para a nomeação dos governadores, os nomes dos prefeitos "indicados" eram submetidos informalmente pelos governadores à aprovação dos militares e formalmente e indiretamente eleitos pelas Assembléias Legislativas estaduais. Agradeço a Celina Souza o esclarecimento deste ponto. 
representação na Câmara dos Deputados passasse de uma média de 1,51 para 1,92. As mudanças foram ainda mais drásticas no Senado, onde a alocação de cadeiras para as unidades subnacionais relativamente pequenas e sem representação anterior significou que o grau médio de superrepresentação aumentou de 2,66 em 1978 para 3,94 em 1995. Na Colômbia, em decorrência das mudanças introduzidas na reforma constitucional de 1991 e da criação de sete cadeiras para departamentos sem representação prévia, o grau médio de super-representação das unidades subnacionais na Câmara dosDeputadosaumentou de 1,17 para 2,73 em $1994 .{ }^{5}$ O Senado, cujas vagas eram distribuídas entre 23 departamentos, de acordo com a população antes de 1991, foi transformado, após a reforma constitucional, em uma câmara proporcionalmente representativa de 100 membros escolhidos a partir de um único distrito eleitoral nacional. $\mathrm{Na}$ Argentina e no M éxico, os graus de super-representação no Senado Federal e na Câmara dos Deputados praticamente não sofreram alterações. A Argentina tinha um grau maior de super-representação de unidades subnacionais no Senado ao longo do período das reformas descentralizadoras (3,15 em 1983 e 3,40 em 1995, após a incorporação da Terra do Fogo) e tinha grau moderadamente elevado de super-representação na Câmara dos Deputados (1,94 em 1983 e 1,85 em 1995). 0 M éxico registrava grau semelhante de super-representação no Senado ao da Argentina em sua Câmara dosD eputados (1,96), tendo permanecido igual ao longo do período. Na Câmara dos Deputados mexicana, a representação era proporcional $(1,00)$. Dessa forma, em termos de grau de alteração na RTI, o Brasil experimentou mais mudanças, seguido, em ordem decrescente, pela Colômbia, pela Argentina e pelo M éxico.

Em resumo, uma visão geral da posição de cada país em cada uma das variáveis revela que, antes das reformas descentralizadoras pós-desenvolvimentistas, o Brasil e a Argentina detinham os níveis absolutos de 
descentralização mais elevados (3,3 e 3,2 de escores agregados de classificação, respectivamente), enquanto o México e a Colômbia detinham os mais baixos (1,8 e 1,7, respectivamente). Isso confirma o que já se sabia sobre a evolução histórica do federalismo e das relações intergovernamentais nesses países (Gibson e Calvo, 2000; Gibson e Falleti, 2004; Samuels, 2003; Souza, 1997). Entretanto, se olharmos para as alterações gerais no equilíbrio do poder, as quais ocorreram após a implementação das políticas de descentralização, veremos que a Colômbia, o Brasil e o M éxico experimentaram mudançassignificativas no equilíbrio do poder, em favor das autoridades subnacionais, com escores médios de classificação das mudanças de 3 , 2,8 e 2,5, respectivamente, ao passo que o equilíbrio intergovernamental do poder na Argentina permaneceu praticamente o mesmo ao longo do período, registrando um escore médio de classificação de 1,7.

Embora as condições iniciais de equilíbrio do poder intergovernamental no Brasil fossem semelhantes às da Argentina no início dos anos 80, isso mudou com a implementação das políticas descentralizadoras pósdesenvolvimentistas, como pode ser visto ao se comparar a primeira coluna de ambos os países. Vinte anos depois, o resultado foi uma transferência significativa de autoridade fiscal, administrativa e política para as instâncias subnacionais do Brasil, aproximando-o mais dos resultad os políticos experimentad os pela Colômbia do que daqueles experimentados pela Argentina, como pode ser visto na comparação da terceira coluna de cada país. Por que, após ter iniciado um processo de descentralização pósdesenvolvimentista com uma estrutura intergovernamental semelhante à da Argentina, os governos subnacionais do Brasil parecem-se mais com os da Colômbia ao final do processo de reformas? Argumento que para responder esta questão, um foco processual, em lugar de um foco estrutural ou institucional de longo prazo, é o maisútil. Apósuma revisão sucinta das possíveis explicações alternativas, destaco, a seguir, como o processo de 
construção, negociação e implementação das reformas nas políticas públicas modela as instituições e a própria política.

\section{Explicações alternativas}

U ma possível explicação das conseqüências da descentralização no grau de alteração no equilíbrio intergovernamental do poder vem da teoria do federalismo de Riker (1964), que argumenta que o grau de autonomia dos governantes subnacionais, após a implementação de reformas descentralizadoras, pode ser explicado pela estrutura interna dos partidos políticos (Garman, Haggard e Willis, 2001). 0 argumento sustenta que, devido a determinados procedimentos eleitorais e de indicação para os cargos eletivos, se os legisladores nacionais são mais leais (accountable) ao Executivo nacional, eles terão uma tendência de pressionar por mais centralização da autoridade no momento de desenhar e negociar reformas descentralizadoras. Se, ao contrário, os legisladores nacionais são mais leais (accountable) aos governantes subnacionais, eles pressionarão por mais descentralização do poder quando essas políticas estiverem sendo negociadas. Este argumento explica adequadamente os níveis absolutos de descentralização antes e depois das reformas. Contudo o argumento não dá conta do grau das mudanças nas relações intergovernamentais. Tanto o Brasil quanto a Argentina têm sistemas partidários descentralizadose legisladores nacionais mais leais às autoridades subnacionais (Eaton, 2002; Garman, Haggard e W illis, 2001; Jones et al., 2002; Samuels, 2003). Entretanto a evolução do equilíbrio intergovernamental do poder em cada caso tem sido radicalmente diferente. ${ }^{6}$ O M éxico, por outro lado, conta com

6 Refiro aqui à lealdade dos parlamentares nacionais que decorre das regras eleitorais e das instituições desses dois países. A afirmação acima não significa que a disciplina partidária no Congresso é inalcançável. Como bem documentado por Figueiredo e Limongi (1999), desde o retorno à democracia, os presidentes no Brasil, talvez com exceção de Fernando Collor de M elo, conseguiram aprovar seus projetos de lei no Congresso. A questão, contudo, permanece: até que ponto essas leis são o resultado 
um sistema partidário centralizado, mas nunca passou por significativa alteração em seu equilíbrio intergovernamental do poder.

A segunda explicação afirma que o grau de mudança nas relações intergovernamentais, trazida pela descentralização, decorre do tipo de divisão territorial de governo estabelecido constitucionalmente. U ma vez que as Constituições federais conferem autonomia para as unidades subnacionais, esta garantia deveria levar a níveis mais elevados de transferência de poder do que aqueles experimentados por Estados unitários (Dahl, 1986). Contudo tanto o Brasil quanto a Argentina são Estadosfederaise, enquanto as políticas de descentralização levaram a mudanças significativas no equilíbrio intergovernamental do poder no Brasil, este não foi o caso na Argentina. Além disso, a Colômbia, apesar do tipo unitário de governo, experimentou nível elevado de mudanças em seu equilíbrio intergovernamental do poder, comparável ao do Brasil.

Por fim, argumenta-se também que as condições iniciais determinam o grau de poder transferido para as esferas subnacionais. Isto significa que os países que são mais centralizados no começo do processo, como o M éxico e a Colômbia, alcançarão um grau mais elevado de transferência de poder para os governos subnacionais do que países que iniciaram o processo com uma distribuição de poder mais equilibrada entre autoridades nacional e subnacionais. Em outras palavras, pode-se dizer que existe um limite máximo para o grau de mudanças que a descentralização pode trazer para as relações intergovernamentais, ou um limite para a devolução de poder para as esferas subnacionais, abaixo do qual um país não pode situar-se. No entanto a evolução do equilíbrio intergovernamental do poder no Brasil desafia este argumento. 0 Brasil iniciou o período pós-desenvolvimentista debate e a votação no Congresso? No caso da Argentina, por exemplo, diversas leis de descentralização e recentralização foram aprovadas por membros do Congresso apenas após as medidas terem sido negociadase acordadas pelo Executivo nacional com os governadores, tanto os de oposição como os pertencentes ao partido do presidente (Falleti, 2003, Capítulo 3). 
com uma estrutura fiscal, administrativa e política no mesmo nível elevado de descentralização que a Argentina. No entanto, ao final do primeiro ciclo de reformas descentralizadoras (nas arenas fiscal, administrativa e política), mais poder foi transferido para governadores e prefeitos. Como podemos explicar estas mudanças?

\section{U ma teoria seqüencial de descentralização}

Para explicar as conseqüências das políticas descentralizadoras pósdesenvolvimentistas na evolução do equilíbrio de poder intergovernamental no Brasil, desenvolvo uma teoria seqüencial da descentralização. A teoria se baseia em três princípios. Primeiro, argumenta-se que a descentralização deve ser concebida como um processo de reformas das políticas estatais. Segundo, a teoria leva em consideração os interesses territoriais de políticos nacionais e subnacionais. Terceiro, a teoria analisa os efeitos da seqüência em que as diferentes políticas descentralizadoras (administrativa, fiscal e política) desdobram-se ao longo do tempo. A seguir, resumo algumas das principais características da teoria. ${ }^{7}$

\section{A descentralização como um processo: origens e tipos}

A descentralização é um processo de reforma do Estado, composta por um conjunto de políticas públicas que transfere responsabilidades, recursos ou autoridade de níveis mais elevados do governo para níveis inferiores, no contexto de um tipo específico de Estado. Dado que essas políticas objetivam reformar o Estado, seu conteúdo e sua interação com os sistemas políticos e econômicos mais amplos, elas se tornam altamente dependen-

7 Para mais detalhes sobre a teoria, ver Falleti (2005, especialmente pp. 328-333). 
tes do tipo de Estado que buscam reformar. Desta forma, defino a origem do processo de descentralização pelo contexto em que o mesmo acontece. Para os propósitos deste artigo, focalizo o processo de descentralização que se inicia com a transição de um tipo de Estado "desenvolvimentista" para um Estado do tipo "bem público" (Block, 1994). No Brasil, como na maioria dos países da América Latina, esta foi a transição de um tipo de Estado desenvolvimentista para um Estado orientado para o mercado (ou neoliberal). Portanto, a seqüência de reformas descentralizadoras pósdesenvolvimentistas analisadas neste artigo começa com a primeira administração que afasta o Estado da intervenção direta na economia e em direção às reformas econômicas pró-mercado. Argumento adiante que, no caso brasileiro, isso ocorreu no último governo militar, de João Figueiredo (1979-1985).

Ao estudar a realocação de autoridade para as esferas subnacionais, muito se pode ganhar de uma taxonomia clara da descentralização com base no tipo de autoridade transferida, que agrega três categorias:

- A descentralização administrativa engloba o conjunto de políticas que transferem a administração e a provisão de serviços sociais como educação, saúde, assistência social e moradia, aos governos subnacionais. A descentralização administrativa pode acarretar a transferência da autoridade na tomada de decisões sobre essas políticas, mas esta não é uma condição necessária. Se receitas são transferidas do centro para cobrir os custos de administração e provisão de serviços sociais, a descentralização administrativa é financiada e coincide com a medida de descentralização fiscal. Se osgovernossubnacionais financiam esses custos com receitas próprias preexistentes, a descentralização administrativa não é financiada.

- A descentralização fiscal se refere ao conjunto de políticas desenhadas para aumentar as receitas ou a autonomia fiscal dos governos subnacionais. As políticas descentralizadoras fiscais podem assumir 
diferentes formas institucionais, tais como o aumento de transferências do governo central, a criação de novos impostos subnacionais ou a delegação da autoridade para cobrar impostos anteriormente cobrados pela esfera federal. ${ }^{8}$

- A descentralização política é o conjunto de emendas constitucionais e de reformas eleitorais desenhadas para abrir novos espaços - ou acionar espaços existentes, mas não utilizados ou ineficazes - para a representação das sociedades subnacionais. A descentralização política transfere autoridade política ou capacidades eleitorais para atores subnacionais. Exemplos deste tipo de reforma são a eleição por voto popular para prefeitos e governadores que, em períodos constitucionais anteriores, eram indicados; a criação de assembléias legislativas subnacionais, e reformas constitucionais que fortaleçam a autonomia política dos governos subnacionais.

Em relação às conseqüências de cada tipo de descentralização no poder subnacional, a hipótese é a de que a descentralização administrativa tenha impacto positivo ou negativo na autonomia dos Executivos subnacionais. Se a descentralização administrativa melhorar as burocracias locais e estaduais, fomentar o treinamento dos governantes locais ou facilitar o aprendizado através da atribuição de novas responsabilidades, melhores serão as capacidades organizacionais dos governos subnacionais. Entretanto, se a descentralização administrativa ocorrer sem a transferência de recursos, a reforma pode reduzir a autonomia dos governantes subnacionais, tornando-os mais dependentes das transferências financeiras nacionais ou aumentarão a dívida subnacional para que possam prover os serviçossociais públicos. De forma semelhante, a descentralização fiscal pode ter impacto positivo ou negativo no grau de autonomia da esfera subnacional. 0 re-

8 Diferente de outras definições de descentralização fiscal que separam a descentralização de receitas da de gastos, nesta definição, descentralização se refere às receitas, enquanto os gastos fazem parte da descentralização administrativa. Esta separação analítica facilita a avaliação das conseqüências dos processos descentralizadores, nos casos em que as transferências de receitas e gastos não caminham na mesma direção. 
sultado dependerá, em grande parte, do desenho da política de descentralização fiscal a ser implementada. Níveis mais elevados de transferências automáticas de recursos aumentam a autonomia dos governantes subnacionais, pois estes se beneficiam das transferências sem serem responsáveis pelos custos, políticos e burocráticos, da arrecadação dessas receitas. Em sentido oposto, delegar autoridade sobre a coleta de impostos para unidades subnacionais sem capacidade administrativa para coletá-los pode trazer sérias restrições aos orçamentos locaise aumentar a dependência dos governantes locais no que se refere às transferências do centro. Por fim, a descentralização política, de acordo com a definição acima, deveria, quase sempre, aumentar o grau de autonomia dos governantes subnacionais em relação ao centro. 0 único caso em que a descentralização política poderia ter efeito negativo no poder dos governadores e prefeitos vis-à-vis níveis mais elevados de autoridade é quando existe aumento da separação de poderes no nível subnacional através, por exemplo, da criação de legislativos subnacionais ou Câmaras M unicipais, o que pode gerar governos subnacionais divididos. Nestes casos, a oposição política subnacional poderia debilitar a autoridade de governadores e prefeitos vis-à-vis o Executivo nacional.

Ao decompor a descentralização dessa maneira, vemosque, dependendo do desenho institucional, as políticas descentralizadoras podem aumentar ou diminuir o poder dos governantes subnacionais em relação ao Executivo nacional. O u seja, não se deve presumir que a descentralização sempre aumenta o poder dos governantes subnacionais. Ao invés disso, a distinção entre os diferentes tipos de políticas descentralizadoras revela que o aumento ou não do poder de governadores e prefeitos depende, em grande parte, do tipo e do desenho de cada política descentralizadora. Dessa forma, dependendo do nível de governo que os políticos representam, eles terão preferências distintas em relação aos diferentes tipos de políticas descentralizadoras. 


\section{Interesses territoriais e poder de barganha dos atores}

Interesses territoriais de presidentes, governadores e prefeitos são definidos pelo nível de governo (nacional, estadual ou municipal) e pelas características da unidade territorial (por exemplo, uma província rica ou pobre, uma cidade grande ou pequena) que representam. Baseada na literatura sobre descentralização e em entrevistas detalhadas com políticos nacionais e subnacionais e com servidores públicos, ${ }^{9}$ descrevo, a seguir, 0 conjunto de preferências dos atores nacionais e subnacionais em relação aos tipos de descentralização.

0 executivo nacional prefere a descentralização administrativa (A) à descentralização fiscal $(F)$, que, por sua vez, é preferível à descentralização política $(P)$, ou A > F > P. A justificativa para esta ordenação é que o governo nacional busca, em primeiro lugar e acima de tudo, livrar-se da responsabilidade pelos gastos. Assim, para um governo nacional, descentralização administrativa é altamente preferível em relação aos outros dois tipos de descentralização. Como argumentam Garman, Haggard e Willis (2001: 209), “N ós esperaríamos que o presidente estivesse mais inclinado a transferir responsabilidades do que recursos para cumpri-las". Se o centro for forçado a escolher entre entregar autoridade fiscal ou política, escolherá transferir autoridade fiscal e manter o controle político, podendo, assim, influenciar a tomada de decisões pelos governantes subnacionais acerca dos gastos.

0 mesmo raciocínio se aplica para explicar a ordem reversa das preferências dos governos subnacionais: $P>F>A$. Sua preferência, em primeiro lugar e acima de tudo, é a descentralização política. Se o presidente não controlar a indicação e a remoção de governadores e prefeitos, estes podem forçar a entrada na agenda de demandase interesses de suas unidades territoriais sem medo de retaliação vinda de cima. Se governadores e prefeitos têm de escolher entre a descentralização fiscal e a administrativa, escolherão a trans- 
ferência de receitas em lugar da transferência de responsabilidades, especialmente se os sindicatos que representam os setores públicos a serem descentralizadosforem grandese fortes. Isto é, os Executivos subnacionais preferem autonomia política, recursose responsabilidades, nesta ordem.

D esta forma, se as políticas descentralizadoras pós-desenvolvimentistas não ocorrerem ao mesmo tempo, mas forem, ao contrário, implementadas em diferentes momentos, é de se esperar que as conseqüências das reformas iniciais tenham impacto no processo de negociação das reformas subseqüentes. Em outras palavras, quando diferentes tipos de descentralização são adotados em momentos diferentes no tempo, podemos esperar efeitos de feedback das políticas ao longo do processo de descentralização, conforme será explicado na próxima seção.

\section{Seqüências da descentralização}

U sando a terminologia de Skowronek (1993: 9), podemos conceber as relações intergovernamentais como uma estrutura em camadas da ação institucional. Políticas descentralizadoras afetam as camadas fiscais, administrativas e políticas das relações intergovernamentais. Raramente uma política descentralizadora afeta simultaneamente todas as três camadas intergovernamentais, embora seja possível. Com maior freqüência, diferentestipos de descentralização, bem como diferentes políticas em cada tipo de descentralização, são negociadas e implementadas em diferentes momentos. Portanto, o timing de cada reforma determina a seqüência da descentralização de um dado país. Se ostrêstipos de descentralização definidos anteriormente ocorrem, o que, teoricamente, não é necessário, mas é comum, podemos identificar seqüências diferentes de descen-tralização, de acordo com o timing da primeira política descentralizadora em cada camada intergovernamental. Isto não significa que políticas descentralizadoras subseqüentes não acontecem em cada camada ou que elas devam ser ignoradas. 
Contudo a seqüência da primeira política descentralizadora em cada camada é especialmente importante, uma vez que impõe constrangimentos no que será factível no restante da seqüência e nos permite estabelecer um modelo básico do impacto de diferentes seqüências de reformas descentralizadoras no equilíbrio intergovernamental do poder.

O nível de governo cujos interesses territoriais prevalecem na origem do processo de descentralização tende a ditar o primeiro tipo de descentralização. A primeira rodada de descentralização, por sua vez, produz efeitos de feedbacknas políticas, seja para seu apoio ou rejeição, o que influenciará a ordem e as características das reformas que virão depois. A seguir, identifico dois tipos de seqüências de descentralização. Elas se caracterizam pela predominância de um tipo de interesses territoriais (nacional ou subnacional) no início da seqüência e pela existência de mecanismos de auto-reforço entre o primeiro e o segundo estágios do processo. ${ }^{10}$

Se os interesses subnacionais prevalecerem no final da primeira rodada de negociações, a descentralização política tem probabilidade de ocorrer primeiro. A descentralização política tem probabilidade de produzir uma política de efeito-catraca (policy-ratchet effect) (Huber e Stephens, 2001: 10), ou seja, que move sempre na mesma direção, o que ocorre quando um grupo de partidários continua a pressionar por mais descentralização. Associações de governad ores, prefeitos ou instâncias semelhantes de coordenação de políticos subnacionais são exemplos da política de efeito-catraca. Fazendo lobby através dessas associações, governadores e prefeitos aumentarão seu poder e suas capacidades para as próximas rodadas de descentralização. M esmo se um mecanismo de coordenação não existir, os governadores e prefeitos estarão em posição melhor para apresentar suas preferências na segunda rodada de reformas porque têm maior autonomia

10 Para a identificação de quatro outras seqüências de descentralização, duas das quais se caracterizam pela existência de mecanismos de reversão, enquanto as outras duas se caracterizam por empate na luta entre interesses territoriais no começo de cada seqüência e suas conseqüências para o equilíbrio intergovernamental do poder, ver Falleti (2005). 
política em relação ao Executivo nacional. 0 presidente, além disso, pode tornar-se dependente de governadorese prefeitoseleitos para a mobilização de votos nas eleições nacionais. Desta forma, na segunda rodada de descentralização, governadores e prefeitos provavelmente demandarão a descentralização fiscal, além de influenciar seus termos. A descentralização administrativa, que provavelmente virá após a descentralização fiscal para compensar pela descentralização dos recursos (Haggard, 1998: 217), será o último tipo de reforma. A descentralização administrativa será, portanto, financiada e não terá impacto negativo no poder de governadores e prefeitos. 0 desfecho final desta trajetória de descentralização $(P \rightarrow F \rightarrow A)$, que atende as preferências dos governantes subnacionais, provavelmente será um alto grau de autonomia para governadores e prefeitos em relação ao presidente. A seguir, mostro que o Brasil seguiu este caminho. ${ }^{11}$

Se, ao contrário, os interesses nacionais prevalecerem no início do processo, a descentralização administrativa tem maior probabilidade de ocorrer primeiro. Se os recursos financeiros não acompanharem a transferência de responsabilidade, o Executivo nacional fortalecerá seu poder visà-vis as instâncias subnacionais, que se tornarão mais dependentes de transferências do centro. Se o processo de descentralização continuar, o presidente fará a opção pela descentralização fiscal em lugar da descentralização política. No entanto, em decorrência do mecanismo de reprodução de poder (power reproduction mechanism) (Stinchcombe, 1968: 117-118), o Executivo nacional controlará o timing, o ritmo e o conteúdo da reforma. Governadores e prefeitos, sob limitação fiscal da primeira rodada de descentralização administrativa sem financiamento, não estarão em posição de rejeitar as condições determinadas pelo centro. Seguindo esta trajetória, a descentralização política, se ocorrer, será o terceiro tipo de reforma e terá efeito residual ou insignificante. 0 desfecho dessa trajetória de reformas $(A \rightarrow F \rightarrow P)$, que privilegia as preferências do Executivo nacional, tem 
probabilidade de trazer pouca ou nenhuma mudança na redistribuição de poder às autoridades subnacionais. A Argentina, por exemplo, seguiu este caminho de 1978 a 1994 (Falleti, 2003; 2005).

\section{Descentralização pós-desenvolvimentista no Brasil}

\section{O rigens do Processo}

No Brasil, entre o Estado desenvolvimentista e o neoliberal, temos a década de 80. (Entrevista com Fabio Giambiagi, economista, IPEA, Rio de Janeiro, 16 de agosto de 2005.)

Enquanto na Argentina, na Colômbia e no M éxico, a identificação do Governo que iniciou o distanciamento do Estado nacional da intervenção na economia e começou a implantação das reformas econômicas neoliberaisé praticamente evidente, este não é o caso do Brasil. ${ }^{12}$ No Brasil, a passagem do Estado desenvolvimentista para o de bem público, como o denomina Block (1994) tem sido gradual, e as políticas orientad as para o mercad o têm sido implementadas de forma menos radical do que nos outros países da América Latina analisados acima. ${ }^{13} \mathrm{~N}$ a verdade, entre a exaustão do modelo desenvolvimentista de crescimento econômico e a implementação das reformas econômicas neoliberais voltadas para o mercado (como as privatizações de empresas estatais e a desregulamentação do comércio), há, no Brasil, uma lacuna de, pelo menos, uma década. Embora as reformas neoliberais não fizessem parte do debate público até a administração de Fernando Collor (1990-1992) e não estivessem completamente implementadas até a primeira administração de Fernando Henrique Cardo-

12 N os países mencionados, os governantes foram, respectivamente, Jorge R. Videla (1976-1981), Belisario Betancur (19821986) e M iguel de la M adrid (1982-1988). É de se observar que governos subseqüentes, como o de Raúl Alfonsín (1983-1989), na Argentina, adotaram políticas econômicastanto ortodoxas quanto heterodoxas, mas o distanciamento do desenvolvimentismo já havia ocorrido. Sobre este ponto, ver Weyland (2002: 72, 77-81).

13 Por Estado de bem público, Block $(1994,691)$ refere-se à idéia de que o Estado deve fornecer apenas bens públicos que 0 mercado não é capaz de produzir sozinho. Neste sentido, bens públicos são definidos como bens ou serviços que, se fornecidos a uma pessoa, podem ser disponibilizados para outras sem custo adicional. Ar puro é um bom exemplo. 0 Estado de bem público é um Estado minimalista que fornece bense serviços que o setor privado não pode produzir com lucro por não poder cobrálos da maioria dos que recebem os benefícios. 
so (1995-1998), o modelo desenvolvimentista de crescimento econômico já estava estagnado e exaurido em 1981.

Enfrentando as privações econômicas causadas pela segunda crise do petróleo e pela crise de endividamento externo dos países da região, 0 governo militar de João Figueiredo (1979-1985) foi o primeiro a afastar o Estado da intervenção direta na economia, colocando um fim nas políticas desenvolvimentistas da administração anterior de Ernesto Geisel (1974-1979). Como escreve Skidmore (1988: 422), "mudanças na economia política foram algumas das medidas anunciadas pelo Presidente Figueiredo em seu discurso de 7 de dezembro de 1979. Adotando uma estratégia de desvalorização e de indexação pré-fixada, D elfim N etto, Ministro da Economia na época, adotou medidas semelhantes às adotadas na Argentina e no Chile. Ele pensava que aqueles países haviam encontrado o caminho para a estabilidade financeira." (Skidmore). Para estabilizar a economia e derrubar a inflação, Delfim N etto implementou medidas de ajuste ortodoxas, semeIhantes àquelas que o FMI estava propondo para os países da região, na época. Como se sabe, essas medidas foram recebidas sem entusiasmo e acabaram falhando, levando à adoção de políticas heterodoxas na administração subseqüente, de José Sarney (1985-1989) (Weyland, 2002: 77-81). U m novo modelo de desenvolvimento econômico não se tornaria completamente visível por outra década. Contudo, na administração de Figueiredo, já estava claro que a segunda fase da política de substituição de importações e o projeto do Estado desenvolvimentista haviam acabado. O sinvestimentos das empresas estatais, um indicador da intervenção direta do Estado na economia, que haviam aumentado regularmente desde 1973, caíram rapidamente após 1979. Enquanto os investimentos nas empresas estatais representavam 8,7\% do PIB em 1979, em 1980 caíram pela metade, 4,3\%, continuando o declínio ao longo da década de 80 , até chegar a $1,8 \%$ do PIB em 1990. Desta forma, como mostra a Figura 1, em 1985, os investimentos de outros setores da administração pública haviam ultrapassado os investimentos das empresas estatais. 
Devido ao fato de o modelo de substituição das importações estar exaurido no Brasil no final da década de 70 e de a administração de Figueiredo ter interrompido as políticas desenvolvimentistas de seu antecessor, começo a análise da seqüência pós-desenvolvimentista das políticas descentralizadoras durante essa administração que tomou posse em 1979.

\section{A primeira camada: descentralização política}

... a decisão de descentralizar foi tomada pelos representantes eleitos e pelos políticos subnacionais, e não pelo governo central. (Souza, 1997: 16)

O Brasil, como a Colômbia, iniciou seu processo de descentralização pós-desenvolvimentista com uma medida de descentralização política (Tabela 2). Em novembro de 1980, o Congresso aprovou a Emenda Constitucional $n^{\circ}$ 15, que restabeleciam a eleição direta para governadores e para todos os membros do Senado, revogando, desta forma, o Ato Institucional $n^{\circ} 3$, de 1966, e parte do "Pacote de Abril", de 1977 (Skidmore, 1988, 441-442). ${ }^{14}$

Embora a emenda, como tantos outros projetos de lei, tenha sido apresentada no Congresso pelo Executivo nacional, diversos fatores realçam a importância das pressões subnacionais na decisão. U ma proposta para a eleição direta dos governadores já havia sido apresentada ao Congresso no início de 1980, pelo Deputado Edison Lobão (PDS, Partido Democrático Social), do M aranhão. ${ }^{15}$ Além disso, assim que o Executivo apresentou sua proposta para a eleição dos governadores e de todos os senadores, os partidos de oposição no Congresso tentaram expandi-la para incluir a eleição direta para presidente, prefeitos e vice-prefeitos das capitais; 0

14 Em abril de 1977, o presidente Geisel fechou o Congresso e anunciou uma série de reformas constitucionais que pretendiam fortalecer a posição do partido oficial, a AREN A, nas eleições de 1978. Todos os governadores e um terço dos senadores seriam eleitos por via indireta pelos colégios eleitorais estaduais; o número de deputados federais por estado seria estabelecido de acordo com a população total do estado, ao invés de pelo número de eleitores registrados, e o acesso dos candidatos políticos à rádio e à televisão seria mais rigoroso (Skidmore, 1988: 373).

150 PDS era o partido que apoiava os militares na época. A proposta foi derrotada em 21 de março de 1980. 


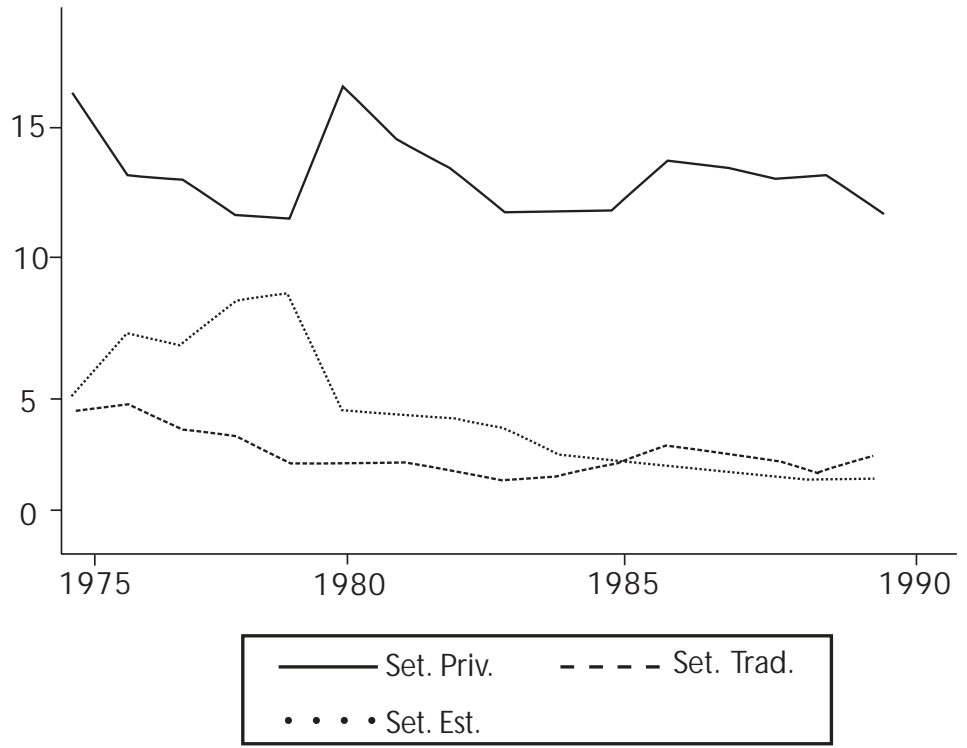

Figura 1 - Investimento real por setor de origem, 1975-1990

Fonte: Coes $(1995,204)$

capitais; o fim dos mandatos dos senad ores eleitos ind iretamente em 1982, antecipando o prazo do ano de 1986 proposto pelo Executivo; a redução do mandato presidencial de seis para cinco anos e a eliminação do colégio eleitoral nacional. ${ }^{16}$ Embora a proposta da oposição não tenha chegado ao plenário do Congresso, ela revela que havia uma demanda para intensificar os processos de democratização e de descentralização, mesmo que o timing e o conteúdo desses processos fossem amplamente controlados de cima pelos militares. A proposta do Governo foi votada e aprovada por unanimidade em 19 de novembro de 1980, a primeira vez desde o Estado Novo

16 "O Congresso A prova a Eleição Direta em 82", na Folha de São Paulo. 14 de novembro de 1980. In "Banco de Dados Folha". Acessado em 12 de abril de 2006, no endereço eletrônico < http://almanaque.folha.uol.com.br/brasil_14nov1980.htm>. 
Sociologias, Porto Alegre, ano 8, no 16, jul/dez 2006, p. 46-85

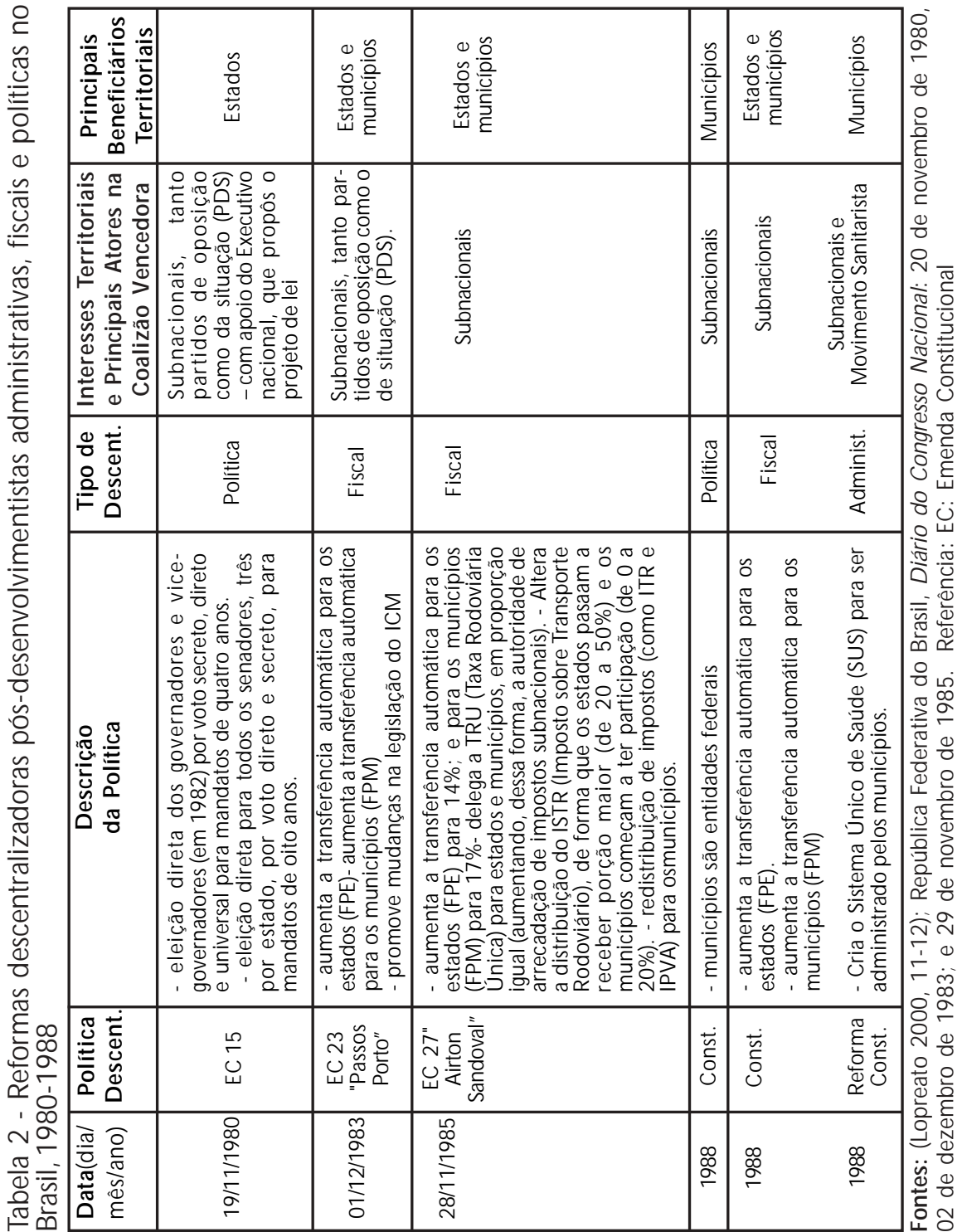


(1937-1945) que uma proposta recebeu unanimidade no Congresso. ${ }^{17}$ Q uando questionados sobre seus planos futuros, pelo menos 55 membros do Congresso disseram que estavam considerando a candidatura a governador em seus estados. ${ }^{18}$

Q uando as eleições diretas para governador aconteceram em 1982, "os governadores eleitos democraticamente ficaram cada vez mais independentes do governo central e controlaram as burocracias do governo estadual" (Samuels, 2004: 79). U ma política de efeito-catraca estava despontando: "o surgimento da influência do governo estadual, combinado com a permanência do controle militar na presidência durante aquela época, aumentou a importância dos atores e dos interesses subnacionais na política nacional, em detrimento dos partidos e das questões nacionais" (ibid). A política de efeito-catraca levaria à negociação do segundo tipo de reforma descentralizadora, a mais importante para os interesses dos governadores após a descentralização política: a descentralização fiscal. Além disso, investidos da legitimidade que decorria da eleição direta (o presidente só seria eleito pelo voto popular em 1989), os governadores (e os atores subnacionais em geral) foram capazes de combinar suas demandas de descentralização com aquelas relacionadas à redemocratização. Como afirma Delfim N etto “... havia uma pressão enorme logo após 1982... o governo não podia mais resistir à pressão dos governadores. Era uma questão de poder. 0 regime autoritário terminou em 1982". (Antonio Delfim N etto, entrevistado em São Paulo, 18 de novembro de 1996, citad o em Samuelse Abrucio, 2000: 57). D esta forma, a descentralização e a redemocratização apareceram no discurso público como parte do mesmo processo.

17 A emenda foi aprovada por 390 votosno Congresso ( 25 deputados estavam ausentes, a maioria do PDS) e 54 votos no Senado (com a ausência de 11 senadores).

18 “O Congresso Aprova a Eleição Direta em 82", na Folha de São Paulo. 14 de novembro de 1980. 


\section{A segunda camada: descentralização fiscal}

Em 1ํ de dezembro de 1983, em meio às pressões sociais para restabelecer as eleições diretas para presidente, o Congresso aprovou a Emenda Constitucional $n^{\circ} 23$, proposta pelo Senador Passos Porto (PDS, Ceará). A emenda aumentava o percentual de transferências federais automáticas para os estados, para o Distrito Federal e para os territórios, através do Fundo de Participação dos Estados (FPE), de 10\% para 14\% e para os municípios (Fundo de Participação dos M unicípios - FPM ), de 10\% para 16\%, mudando também alguns aspectos da legislação do então ICM . Como Celina Souza escreve: "O lobby a favor dos municípios era, há tempos, forte no Congresso. Em 1979, o Congresso instalou uma CPI para analisar as "causas do crescente empobrecimento dos estados e municípios". 0 relatório final da CPI acusava o governo federal de tirania fiscal e afirmava que os governos subnacionais estavam à beira do colapso, com sérias conseqüências para a ordem social. 0 relatório concluiu que a centralização afetava a autonomia dos estados, mas, acima de tudo, a dos municípios" (Souza, 1997: 68).

A medida descentralizadora fiscal introduzida pela Emenda Passos Porto foi acompanhada de outra, proposta pelo Deputado Airton Sandoval (Partido do M ovimento Democrático Brasileiro, ou PMDB, São Paulo), em 1984, e aprovada pelo Congresso em 28 de novembro de 1985 (Emenda Constitucional $n^{\circ} 27$ ). A emenda ampliou a autoridade de arrecadação de impostos municipais e aumentou as transferências federais automáticas para estados e municípios (Tabela 2).

Essas medidas deram início a um processo de descentralização fiscal que atingiria seu clímax na Constituição de 1988 (Souza, 2001: 519). Como M onteiro escreve, "imbuídas de autonomia política e de recursos [por causa da eleição direta para governadorese as reformas fiscais de 1983 e 1984/ 85], as bancadas subnacionais emergiram em sua posição mais forte duran- 
te a N ova República [após 1985]. Elas exerceram sua influência mais claramente na Assembléia Constituinte de 1987-1988, em que desempenharam papel de liderança na formação das regras do federalismo fiscal para favorecer a autonomia subnacional" (Montero, 2004: 147). Além disso, durante a reforma constitucional, a descentralização política - especialmente beneficiando o nível municipal do governo - também continuou. Ao aprofundar a descentralização política e fiscal, os interesses subnacionais foram os mais importantes.

\section{A Reforma Constitucional de 1988: aprofundando a descentralização política e fiscal}

O s559 membros do Congresso (72 senadores e 487 deputados) eleitos em 1986 compunham a Assembléia Nacional Constituinte que elaborou a Constituição de 1988, a qual se caracterizou pela predominância dos interesses subnacionais. 0 presidente José Sarney havia sido eleito por voto indireto, ao passo que os constituintes, os governadores e os prefeitos haviam sido eleitos por voto popular e podiam alegar legitimidade eleitoral. Além do mais, Sarney foi um presidente fraco, e o Executivo nacional como que ficou muito ausente das negociações com os constituintes, entre os quais estavam antigos governadores e prefeitos. Sarney concentrou seus esforços na luta pela extensão do mandato presidencial, de cinco para seis anos, e fez concessões significativas em troca. Seu principal oponente e presidente da Constituinte, Ulysses Guimarães, um líder influente e carismático do PM D B, deu voz não apenas às exigências da oposição, mas também àquelas dos governos subnacionais. Como Celina Souza escreve, com base em entrevista com o então Senador Jarbas Passarinho, "Sarney era prisioneiro de U lysses. O PMDB retardou o máximo possível a decisão em relação ao mandato de Sarney para mantê-lo sob controle" (Souza, 1997: 61). 
A nova Constituição aprofundou o processo de descentralização política e fiscal. No campo político, os municípios foram reconhecidos como membros integrantes da Federação. Portanto, desde a Constituição de 1988, os municípios têm o mesmo status constitucional dos estados (artigo 18 da Constituição de 1988). Um novo estado foi acrescentado à federação, Tocantins, recortado do estado de Goiás, e dois territórios passaram à condição de estados. Isso teve como conseqüência o aumento da representação dos interesses dos estados da Região N orte no Congresso. No campo fiscal, tanto os estados quanto os municípios tiveram assegurados níveis mais elevad os de transferências federais automáticas. Além disso, o Governo Federal perdeu alguns impostos específicos, como os sobre combustíveis, lubrificantes, comunicações e eletricidade, que passaram a integrar 0 imposto de valor agregado estadual, o ICMS. 0 impacto das medidas descentralizadoras fiscais na evolução das receitas totais de cada nível de governo pode ser visto na Figura 2.

$\mathrm{N}$ a identificação do tipo de interesses territoriais por trás das coalizões que forçaram as reformas políticas e fiscais descentralizad oras, mais evidências podem ser obtidas na análise das subcomissões e das comissões da Constituinte, feita por Celina Souza. ${ }^{19} \mathrm{O}$ relator da subcomissão sobre municípios e regiões propôs a inclusão do município como parte do pacto federal e o aumento das receitas locais. "Ao justificar a proposta de expansão das receitas dos municípios, o relator [Aloysio Chaves (PFL-PA)] argumentou que havia um clamor de prefeitos, vereadores, profissionais da saúde, líderes comunitários e do povo a favor do fortalecimento do município" (Souza, 1997: 67. Grifo meu). Com relação à criação do estado de Tocantins, que, antes da Constituinte, havia sido aprovada pelo Congresso,

19 O s próximos parágrafos estão baseados na excelente análise da Assembléia N acional Constituinte realizada por Celina Souza (1997, em especial oscapítulos 3 e 4). 


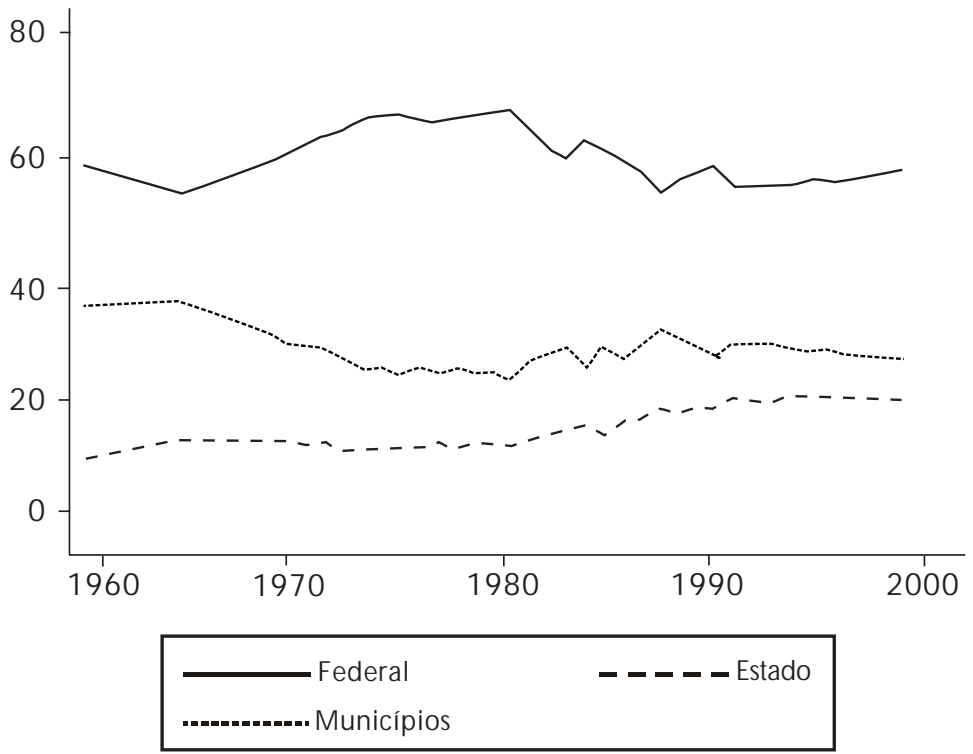

Figura 2 - Receitas totais (após transferências), por nível de Governo, Brasil 1960-2004

Fonte: Varsano et alii (1998), com atualização dos dados dos anos de 1997 a 2004 (estimativa de 2004) feita por Amir Kahir.

mas vetada por Sarney, os interesses dos constituintes prevaleceram sobre os do Governo Federal. ${ }^{20}$

Enquanto isso, a descentralização administrativa que, como mencionado em seção anterior, é o tipo de reforma descentralizadora mais importante para o governo central e a menos desejada pelas autoridades subnacionais, não teve avanços com a Constituição de 1988. Embora recursos tenham sido redistribuídos para os governos subnacionais, as responsa-

20 Apesar da aparente pressão dos interesses subnacionais levando a essas reformas políticas, Celina Souza argumenta que as pressões subnacionais mais importantes na Constituinte ocorreram no campo fiscal e não na área das reformas das relações intergovernamentais. Essa área, ela argumenta, ficou restrita ao território da política paroquial e aos interesses das regiões menos desenvolvidas (Souza, 1997: 70). 
bilidades foram amplamente mantidas como competências concorrentes entre os níveis de governo, sem qualquer regra sobre como essas competências seriam compartilhadas (Souza, 1997: 43-44).

\section{A terceira camada: descentralização administrativa}

Sarney tentou transferir a responsabilidade pela provisão de alguns serviços públicos para estados e municípios, através do que ficou conhecido como 0 peração D esmonte, mas suas tentativas falharam em decorrência da oposição da burocracia federal, que não queria abrir mão do controle dos serviços, e a dos governadores e prefeitos, que não queriam a transferência de responsabilidades sem a garantia dos recursos financeiros (Affonso, 1998: 710-711; Souza, 1997: 51).

Diferentemente da Argentina, da Colômbia e do México onde a descentralização administrativa se iniciou no setor da educação, no Brasil, a descentralização administrativa começou no setor da saúde. Além disso, diferentemente daqueles países onde a descentralização administrativa foi incentivada quase exclusivamente pelo Executivo nacional, no Brasil houve um grupo influente de ativistas do setor da saúde, o movimento sanitarista, que defendia a descentralização para o nível municipal. ${ }^{21}$ Eles também demandavam um sistema de saúde com cobertura universal, totalmente financiado e administrado pelo sistema público. Esse movimento teve presença marcante na Constituinte. A demanda pela cobertura universal foi contemplada na Constituição, que substituiu o sistema IN AM PS pelo sistema SU S (Sistema Ú nico de Saúde). ${ }^{22}$ A demanda por um sistema de saúde completamente financiado por recursos públicos não teve sucesso por cau-

210 movimento sanitarista foi formado no final da década de 70 por profissionais da saúde, autoridades sanitaristas locaise especialistas em saúde, de esquerda (Arretche, 2004: 166-167).

220 INAM PS, ou Instituto Nacional de Assistência M édica da Previdência Social, administrava os recursos, a contratação e o pagamento dos profissionais da saúde que atuavam no sistema nacional antes de 1988 (Arretche, 2004: 159). 
sa do lobby do setor privado da saúde, e tanto a cobertura pública quanto a privada foram incluídas na Constituição.

Em relação à descentralização, avanços significativos ocorreram no final da década de 80, em termos de administração dos serviços de saúde. Em 1981, apenas 22\% do número total de estabelecimentos de saúde estavam sob responsabilidade municipal, $50 \%$ sob responsabilidade estadual, e 28\% nas mãos do Governo Federal (Arretche, 2004: 160: 4). Em 1989, esses mesmos números eram 45\%,46\% e 9\%, respectivamente (os cálculos foram feitos com base em dados de Arretche, 2004: 162). As fontes de financiamento da saúde pública, contudo, continuaram largamente em poder do Governo Federal. Em 1989, 80\% do financiamento dos serviços de saúde pública era federal, $9 \%$ dos estados e $11 \%$ dos municípios (Arretche, 2004: 163). A descentralização do financiamento dos serviços de saúde pública ocorreu na década de 90 . Em 1996, o Governo Federal financiava $53 \%$, os estados $18 \%$ e os municípios $28 \%$ das despesas dos serviços de saúde pública (Arretche, 2004: 163).

\section{Conclusão}

Embora o Brasil tenha iniciado seu processo de descentralização pósdesenvolvimentista em condições semelhantes às da Argentina, ao final do processo, o Brasil havia passado por tantas mudanças quanto as que também ocorreram em um país anteriormente centralizado como a Colômbia. Antes do processo pós-desenvolvimentista, as estruturas intergovernamentais do Brasil e da Argentina eram semelhantes. Ao final do primeiro ciclo de reformas descentralizadoras, isto é, uma vez que as políticas descentralizadoras nas arenas política, fiscal e administrativa foram implantadas após o colapso do Estado desenvolvimentista e do modelo econômico, a estrutura intergovernamental do Brasil passou pelo mesmo tipo de mudanças radicais que um país unitário como a Colômbia. No Brasil, especialmente durante a 
década de 80 e o início dos anos 90, parcela significativa do poder foi transferida para os estados e municípios.

As teorias que focalizam o tipo de divisão territorial de governo, o grau de lealdade (accountality) dos legisladores nacionais aos políticos nacionais ou aos subnacionais, ou explicações que levam em consideração as condições iniciais, não conseguem explicar o grau de mudanças que as reformas descentralizadoras trouxeram para os quatro maiores países da América Latina. Essas teorias podem responder pelo nível de descentralização dos países em momentos específicos, mas não são capazes de explicar a dinâmica do processo de descentralização. Para entender o grau de mudança que as políticas, no caso, as políticas descentralizadoras, trazem para as instituições, a abordagem processual é mais promissora.

Ao analisar o processo de descentralização pós-desenvolvimentista no Brasil, especialmente em seus estágios iniciais, de 1980 a 1988, período freqüentemente negligenciado nas pesquisas, focalizei o médio prazo. N ão investiguei as causas da descentralização no longo prazo, o que implica considerar características institucionais mais enraizadas, tais como o tipo de federalismo ou das instituições intergovernamentais. Tampouco investiguei as causas e as características da descentralização a partir da racionalidade dos atores individuais ou dos incentivos eleitorais, tais como os ganhos eleitorais ou financeiros esperados, que compõem uma abordagem de curto prazo. Ao invés, situei o processo analisado, no caso, o processo de descentralização, em seu contexto conceitualmente relevante, ou seja, o Estado pós-desenvolvimentista que as políticas descentralizadoras analisadas neste artigo buscaram reformar, e identifiquei os principais atores sociais e políticos que impulsionaram esse processo. Ao fazer isso, focalizei o médio prazo, um período que, neste trabalho, abrange entre uma e duas décadas. Desta forma, examinei as causas e as características das mudanças trazidas pela descentralização ao equilíbrio intergovernamental do poder nos diferentes tipos de coalizões que impulsionaram as reformas descentralizadoras e no tipo de interesses territoriais que os atores desse processo representa- 
vam. Além disso, uma vez que no processo estudado as reformas anteriores afetaram a exeqüibilidade e as características das reformas posteriores, analisei o impacto que as políticas descentralizadoras implantadas em uma arena ou em uma das camadas das relações intergovernamentais - política, fiscal e administrativa - têm umas sobre as outras.

Durante os anos 90 e os anos 2000, as relações intergovernamentais passaram por mudanças significativas. Algumas delas, como a Lei de Responsabilidade Fiscal, até mesmo reverteram ou tentaram corrigir os efeitos de políticas descentralizadoras anteriores. Excelentes artigos de especialistas já analisaram essas mudanças mais recentes. Este artigo não pretende apresentar a palavra final sobre a situação atual da federação brasileira, dos estados e dos municípios. Ao contrário, seu principal objetivo é comparar os estágiosiniciais do processo de descentralização pós-desenvolvimentista com aqueles que ocorreram em outros países da América Latina e mostrar que a forma como a seqüência de reformas se inicia tem grandes conseqüências sobre como o resto do processo se desenvolverá e sobre o equilíbrio intergovernamental do poder. Desta forma, propusuma explicação seqüencial da descentralização que responde pelos resultados hoje observados.

0 artigo mostra que um processo descentralizador que começa com a descentralização política, continua com a descentralização fiscal e termina com a descentralização administrativa, dá poderes aos governos subnacionais. Isso ocorre independentemente do tipo de governo, das condições iniciais das estruturas institucionais intergovernamentais e também, em grande parte, independentemente da lealdade dos parlamentares à estrutura partidária. Em outras palavras, são as características do processo, isto é, que interesses territoriais dominam em cada instância de negociação das políticas descentralizadoras e o timing das reformas, que explicam 0 grau de mudança do equilíbrio intergovernamental do poder entre governos nacional e subnacionais. 
Referências

ABRU CIO, Fernando Luiz. Os Barões da Federação. Os governadores a e redemocratização brasileira. São Paulo: Editora Hucitec. Departamento de Ciência Politica, USP. 1998.

AFFO NSO, Rui de Britto A. La Federación en Brasil: Impasses y perspectivas. In: Las regiones ante la globalización, competitividad territorial y recomposición sociopolítica. Mexico: El Colegio de Mexico, Centro de Estudios Internacionales, 691-716.1998.

ARRETCHE, M arta. Toward a U nifiedand More Equitable System: Health Reform in Brazil. In: Crucial Needs, Weak Incentives. Social Sector Reform, Democratization, and Globalization in Latin America, edited by KAU FM AN , R. R. and NELSO N, J. M. Washington, D.C., Baltimore and London: Woodrow Wilson Center Press and The Johns Hopkins U niversity Press, 155-188.2004.

BLO CK, Fred. The Roles of the State in the Economy. In: Handbook of Economic Sociology, edited by SMELSER, N. and SWEDBERG, R. Princeton: Princeton University Press, 691-710.1994.

BURKI, SH AHID J., GU ILLERM O, E. Perry, and WILLIAM, R. Dillinger. Beyond the Center: Decentralizing the State. Washington, DC: The World Bank.1999.

COES, Donald V. Macroeconomic Crises, Policies, and Growth in Brazil, 196490. Washington, D.C.: The World Bank.1995.

CO RRALES, Javier. M ultiple Preferences, Variable Strengths: The Politics of Education Reform in Argentina. In: Crucial Needs, Weak Incentives: Social Sector Reform, Democratization, and Globalization in Latin America, edited by KAU FM AN, R. R. and NELSO N, J. M. Washington, DC and Baltimore, MD: Woodrow Wilson Center Press and Johns Hopkins U niversity Press, 315-349.2004.

DAHL, Robert. "Federalism and the Democratic Processs. In: Democracy, Liberty, and Equality. O slo, Denmark: N orwegian U niversity Press, 114-26. 1986.

SANTOS, Wanderley Guilherme dos. Governadores-Políticos, GovernadoresTécnicos, Governadores-Militares. Dados 8:123-28.1971.

DRAIBE, Sônia M. Chapter 13. Federal Leverage in a Decentralized System: Education Reform in Brazil. In: Crucial Needs, Weak Incentives. Social Sector 
Reform, Democratization, and Globalization in Latin America, edited by KAUFM AN, R. R. and NELSO N, J. M. Washington, D.C., Baltimore and London: Woodrow Wilson Center Press and The Johns Hopkins University Press, 375406.2004.

EATO N, Kent. Fiscal Policy Making in the Argentine Legislature. In: Legislative Politics in Latin America, edited by M O RGEN STERN, S. and NACIF, B. Cambridge, UK, New York, NY: Cambridge University Press, 287-314.2002.

FALLETI, Tulia G. Governing Governors: Coalitions and Sequences of Decentralization in Argentina, Colombia, and Mexico. Ph.D. Thesis, Political Science, Northwestern University.2003

A Sequential Theory of Decentralization: Latin American Cases in Comparative Perspective. American Political Science Review 99 (3):327-346.2005

FIGUEIRED O, Argelina Cheibub, and LIMO NGI, Fernando Limongi. Executivo e Legislativo na nova ordem constitucional. Rio de Janeiro: FGV.1999.

GARM AN, Christopher, HAGGARD, Stephan and WILLIS, Eliza. 2001. Fiscal Decentralization. A Political Theory with Latin American Cases. World Politics 53 (January):205-236.2001.

GIBSO N, Edward L., and CALVO, Ernest. Federalism and low-maintenance constituencies: Territorial dimensions of economic reform in Argentina. Studies in Comparative International Development 35 (3):32-55.2000.

GIBSO N, Edward L., and FALLETI, Tulia. U nity by the Stick: Regional Conflict and the $O$ rigins of Argentine Federalism. In: Federalism and Democracy in Latin America, edited by GIBSO N, E. Baltimore and London: The Johns Hopkins U niversity Press, 226-254.2004

H AG GARD, Stephan. La reforma del estado en América Latina. Reforma y democracia 11:189-230.1998.

H AGO PIAN, Frances. Traditional politics and regime change in Brazil. Cambridge, New York, M elbourne: Cambridge U niversity Press.1996.

HUBER, Evelyne, and STEPHENS, John D. Development and Crisis of the Welfare State. Parties and Policies in Global Markets. Chicago and London: University of Chicago Press.2001. 
JONES, Mark P., et al. Amateur Legislators-Professional Politicians: The Consequences of Party-Centered Electoral Rules in a Federal System. American Journal of Political Science 46 (3):656-669.2002.

LAM O UN IER, Bolívar. De Geisel a Collor: o balanço da transição. São Paulo: Editora Sumaré Ltda. IDESP.ed.1990 .

LO PREATO, Franciso Luiz C. Federalismo e finanças estaduais: algumas reflexões. IE/U NICAM P, September, Texto para Discussão N o. 98.2000.

MONTERO, Alfred P. Competitive Federalism and Distributive Conflict. In: Reforming Brazil, edited by FONT, M. A. and SPANAKOS, A. P. Lanham, MD: Lexington Books, 137-159.2004.

RIKER, William H. Federalism. O rigin, O peration, Significance. Third ed. Boston and Toronto: Little, Brown and Co.1964.

SAMU ELS, David. Ambition, Federalism, and Legislative Politics in Brazil. New York: Cambridge University Press.2003.

.The Political Logic of Decentralization in Brazil." In Decentralization and Democracy in Latin America, edited by A. P. Montero and D. J. Samuels. Notre Dame, IN: U niversity of N otre Dame Press, 67-93.2004.

SAMUELS, David, and ABRUCIO, Fernando Luiz. Federalism and Democratic Transitions: The "New" Politics of the Governors in Brazil. Publius: The Journal of Federalism 30 (2):43-61.2000.

SCHNEIDER, Ben Ross. The Desarrollista State in Brazil and Mexico. In: The Developmental State, edited by W O O CU M INGS, M. Ithaca and London: Cornell U niversity Press, 276-305.1999.

SKID M O RE, Thomas E. Brasil: de Castelo a Tancredo, 1964-1985. Rio de Janeiro: Paz e Terra.1988.

SKOW RO NEK, Stephen. The Politics Presidents Make. Leadership from John Adams to George Bush. Cambridge, M A and London: The Belknap Press of H arvard U niversity Press.1993.

SO U ZA, Celina. Constitutional Engineering in Brazil. The Politics of Federalism and Decentralization. New York, NY: St. M artin's Press, Inc.1997. 
SO UZA, Celina. Federalismo e Descentralização na Constituição de 1988: Proceso Decisório, Conflitos e Alianças. DAD O S - Revista de Ciências Sociais 44 (3):513-560.2001.

STEN PAN, Alfred. Brazil's D ecentralized Federalism: Bringing Government Closer to the Citizens? Daedalus 129 (2):145-169.2000.

STIN CHCO M BE, Arthur L. Constructing Social Theories. N ew York, Chicago, San Francisco, Atlanta: Harcourt, Brace \& World, Inc.1968.

TAVARES, M aria Hermínia de Almeida. Federalismo y Políticas Sociales [Federalism and Social Policies]. 1-38.

W EYLAND, Kurt. The Politics of Market Reforms in Fragile Democracies. Argentina, Brazil, Peru, and Venezuela. Princeton and Oxford: Princeton University Press.2002.

\section{Resumo}

Este artigo analisa os efeitos de políticas de descentralização na evolução das relações de poder entre presidentes, governadores e prefeitos no Brasil, após o fim do estado desenvolvimentista. Compara as conseqüências da descentralização pós-desenvolvimentista no Brasil com aquelas resultantes de processos similares na Argentina, na Colômbia e no México. Para explicar as diferenças observadas entre os países, o artigo desenvolve uma teoria seqüencial da descentralização, a qual é aplicada ao caso brasileiro.

Palavras-chave: relações intergovernamentais, descentralização administrativa, descentralização fiscal, descentralização política, descentralização na saúde. 


\section{Effects of decentralization on cross-government relations: Brazil from a comparative perspective}

\section{Tulia Falleti}

This article analyzes the effects of decentralization policies on the evolution of the balance of power among presidents, governors, and mayors in Brazil after the demise of the developmental state. It compares the consequences of postdevelopmentalist decentralization in Brazil to those that the similar processes had in Argentina, Colombia, and Mexico. To explain the differences observed among countries, the article advances a sequential theory of decentralization, which is then applied to the Brazilian case.

Key Words: Decentralization, Intergovernmental Relations, Brazil, Argentina, Colombia, M exico, Administrative Decentralization, Fiscal Decentralization, Political Decentralization, Emenda Constitucional No. 15 of 1980, Emenda Constitucional No. 23 "Passos Porto" of 1983, Decentralização Saúde. 